\title{
Separation of waste lubricating oil by molecular distillation
}

\author{
Zhaomei Meng $^{1, a}$, Zhongjun $\mathrm{Fu}^{1, \mathrm{~b}}$ and Zhendong $\mathrm{Fan}^{1, \mathrm{c}}$ \\ ${ }^{1}$ School of Chemical Engineering, Shandong University of Technology, Zibo 255049, China \\ amengzmei@163.com, byls9693@163.com, '1026072053@qq.com
}

Keywords: molecular distillation, lubricating oil.

\begin{abstract}
In this paper, the influence factors of separation of waste lubricating oil by molecular distillation were studied, and the optimal conditions were determined. The preheating temperature, system pressure, distillation temperature and feeding rate had main influence on yield and viscosity index of lube base oil analyzed by single factor experiment. The optimal technological conditions were preliminarily found as follows: preheating temperature $170{ }^{\circ} \mathrm{C}$, operation pressure $70 \mathrm{~Pa}$, distillation temperature $200{ }^{\circ} \mathrm{C}$ and feeding rate $8 \mathrm{~kg} / \mathrm{h}$. Under these conditions, the recovery rate of waste lubricating oil was over $50 \%$, which could realize the comprehensive utilization of the resources.
\end{abstract}

\section{Introduction}

Lubricating oil will deteriorated in the process of mechanical transmission, its performance index decreased to a certain degree must be replaced, and then a lot of waste lubricating oil was produced. If the waste lubricating oil which cannot meet the function of lubrication was directly discarded or burned, it is not only a serious waste of resources, but also a pollution of environment [1, 2]. The comparison of economic and technical parameters for the regeneration technology of waste lubricating oil in foreign countries was carried out by Yu-Lung Hsu [3] and other scholars. He suggested that government and the environmental protection administration department should carry out policy to support the enterprises and develop new technologies to improve the recovery of waste lubricating oil resource.

Molecular distillation [4] is an efficient non equilibrium distillation technology, which has the advantages of low operating temperature, high separation efficiency and low environmental pollution. Now it is widely used in various types of chemical industry [5, 6]. Because the distillation temperature is much lower than the pyrolysis temperature of the lubricating oil in the molecular distillation process, the index of the lube base oil distilled is equal to the new oil and whole process of safe and environmental friendly. In this paper, the waste lubricating oil was used as raw material, the yield and viscosity index were selected as the indexes, the influence of molecular distillation operation parameters on these functional indexes was investigated through the single factor experiment and the influence principle was analyzed.

\section{Materials and Methods}

Materials. The waste lubricating oil was provided by an automobile service factory in Shan Dong province and its physical and chemical properties measured by experiments were given in Table 1 . The analytically pure petroleum ether, toluene, acetone and heptane were used in these experiments. 
Tab 1 The properties data of waste lubricating oil

\begin{tabular}{ccc}
\hline Project & Number & Testing standard \\
\hline Density $\left(\mathrm{g} / \mathrm{cm}^{3}\right)$ & 0.881 & GB/T1884-92 \\
Water $(\%)$ & 0.11 & GB/T260-77(88) \\
Kinematic viscosity $\left(\mathrm{mm}^{2} / \mathrm{s}, 100{ }^{\circ} \mathrm{C}\right)$ & 14.23 & GB/T265-88 \\
Mechanical impurities (\%) & 0.24 & GB/T511-88 \\
Carbon residue $(\%)$ & 1.77 & GB/T268-87 \\
Flash point $\left({ }^{\circ} \mathrm{C}\right)$ & 190 & GB/T3536-88 \\
\hline
\end{tabular}

Experimental apparatus. Molecular distillation device $(15 \mathrm{~kg} / \mathrm{h})$, kinematic viscosity tester (SYD-265C), inspection densimeter, kang carbon residue oil product tester (DYH-127) and flash point tester.

Pretreatment of raw material. The waste lubricating oil was placed in the container at room temperature for settlement with 48h, and then the free water, sludge and other solid impurities can be removed from the oil. After settlement was completed, the upper part of the oil was selected as the experimental material. The experimental raw material was heated to $130{ }^{\circ} \mathrm{C}$ and was fed into a thin film evaporator for distillation to remove the water and the light components such as gasoline, solvent oil in the raw material.

Kinematic viscosity and viscosity index (VI). The kinematic viscosity of lube base oil was tested according to national standard (GB/T265-88) and the viscosity index was calculated by formula (1). The viscosity index indicates that the viscosity of the oil changes with the temperature. High viscosity index indicates that the viscosity of lubricating oil was little affected by the temperature, and the quality of the oil was better.

$\mathrm{VI}=[(\mathrm{L}-\mathrm{U}) /(\mathrm{L}-\mathrm{H})]$

In formula (1), $\mathrm{H}$ represents the viscosity of known oil at $40^{\circ} \mathrm{C}$ and the viscosity index of known oil was 100 . L represents the viscosity of known oil at $40{ }^{\circ} \mathrm{C}$ and the viscosity index of known oil was 0 . $\mathrm{U}$ represents the viscosity of testing oil at $40^{\circ} \mathrm{C}$.

\section{Results and Discussion}

The effect of preheating temperature. Under the conditions of the pressure $70 \mathrm{~Pa}$, the distillation temperature $200{ }^{\circ} \mathrm{C}$ and feeding rate $8 \mathrm{~kg} / \mathrm{h}$, the product yield and the viscosity index were obtained respectively under the preheating temperature of 140, 150, 160, 170, 180 and 190 ${ }^{\circ} \mathrm{C}$. The results were shown in Fig. 1.

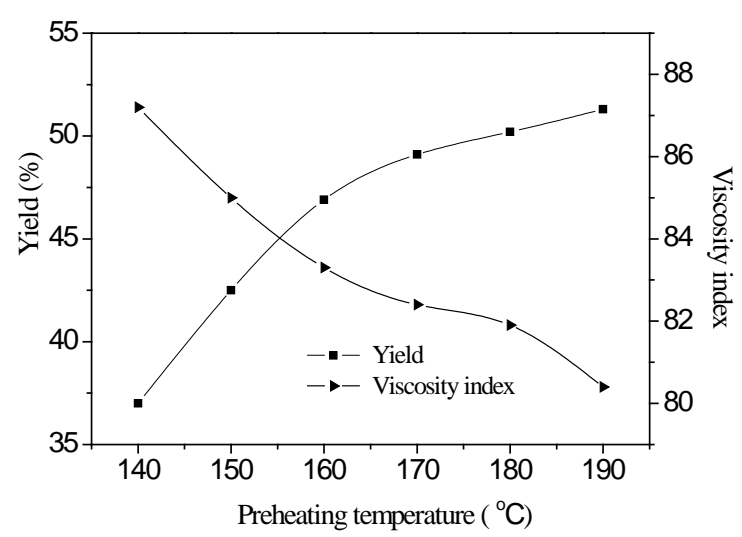

Fig. 1 The effect of preheating temperature

As shown in Figure. 1, the fluidity of waste lubricating oil was poor because of the low preheating temperature, meanwhile, the efficiency of mass and heat transfer was low. Consequently, the whole molecular distillation efficiency and the yield of product were undesirable. But the viscosity index of oil was high and product oil had good quality. With the increase of preheating temperature, lubricant yield increases, and the heavy components were removed out by distillation such as aromatics, resinous substance and asphalt, then oil viscosity index decreased and product 
quality becomes poor. When preheating temperature was $160^{\circ} \mathrm{C}$, the yield of product has reached a high level. If preheating temperature exceeds $170{ }^{\circ} \mathrm{C}$, the yield of product does not display a remarkable improvement. Taking all these factors into account, the best preheating temperature was $170{ }^{\circ} \mathrm{C}$.

The effect of system pressure. Under the conditions of the preheating temperature $170{ }^{\circ} \mathrm{C}$, the flow rate $8 \mathrm{~kg} / \mathrm{h}$ and the distillation temperature $200{ }^{\circ} \mathrm{C}$, the product yield and the viscosity index were obtained respectively under the pressure of 40,50,60, 70, 80 and 90Pa. The results were shown in Fig. 2.

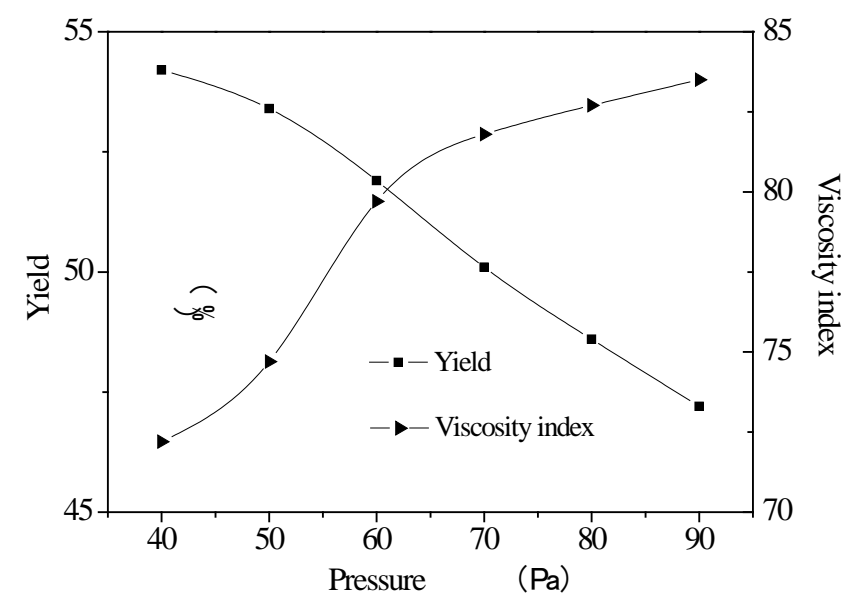

Fig. 2 The effect of system pressure

As shown in Figure. 2, when the pressure was low, the product yield was in high lever. However, the viscosity index was low and the quality of the oil was poor. As the pressure of molecular distillation increasing, the yield of product decrease, the viscosity index is high and the quality of the oil product increases. When the system pressure was 70Pa, the yield of lubricating oil was in high lever. The product yield was $50.1 \%$ and the viscosity index was 81.8. It is up to the standard of lube base oils. Hence, the optimum pressure was 70Pa.

The effect of distillation temperature. Under the conditions of the system pressure $70 \mathrm{~Pa}$, the preheating temperature $170{ }^{\circ} \mathrm{C}$ and the flow rate $8 \mathrm{~kg} / \mathrm{h}$, the product yield and the viscosity index were obtained respectively at the distillation temperature of $170,180,190,200,210$ and $220^{\circ} \mathrm{C}$. The results were shown in Fig. 3.

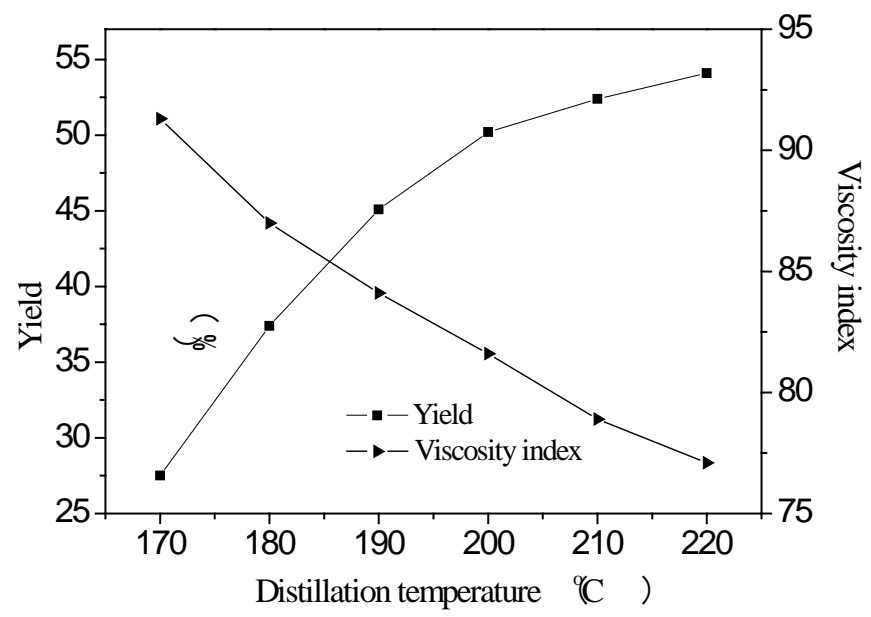

Fig. 3 The effect of distillation temperature

As shown in Figure. 3, when the distillation temperature was at low lever, the light component on the surface of the evaporation was less to reach boiling point, so the viscosity index was high and the quality of the oil product was good. With the evaporation surface temperature increases, more and more heavier component reaches boiling point to escape from the liquid, such as colloid 
and asphaltene, etc. At the temperature of $200^{\circ} \mathrm{C}$, the yield changed slowly. The yield was about $50.2 \%$ and the viscosity index was about 81.6. It was up to the standard of lube base oils. From the above, the optimum distillation temperature was $200{ }^{\circ} \mathrm{C}$.

The effect of feeding rate. Under the conditions of the pre-heating temperature $170{ }^{\circ} \mathrm{C}$, the distillation temperature $200{ }^{\circ} \mathrm{C}$ and the system pressure $70 \mathrm{~Pa}$, the product yield and the viscosity index were obtained respectively at the flow rate of $2,4,6,8,10$ and $12 \mathrm{~kg} / \mathrm{h}$. The results were shown in Fig. 4.

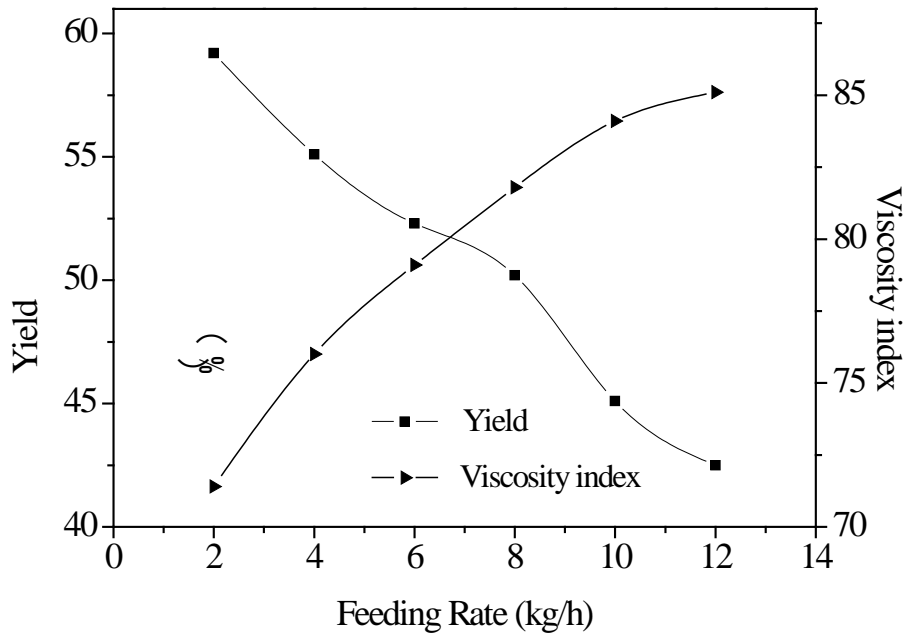

Fig.4 The effect of feeding rate

As shown in Figure. 4, under the certain distillation temperature and system pressure, when the feeding rate was low, the product yield was in high lever, the viscosity index was low and the quality of the oil product was poor. With the increase of the feeding rate, the energy needed to reach the evaporation temperature increases gradually. The energy supplied by the system cannot meet the requirement that the materials evaporate. Meanwhile, the product yield was low, the viscosity index was high and the quality of the oil product was good. At the feeding rate of $8 \mathrm{~kg} / \mathrm{h}$, the yield was about $50.2 \%$ and the viscosity index was about 81.8 . The feeding rate continues to increase, the yield decreases. So the optimal feeding rate was $8 \mathrm{~kg} / \mathrm{h}$.

\section{Conclusion}

Through the research of the main technological parameters and the optimization of the process conditions, the efficiency of the molecular distillation separation of waste lubricating oil was improved. The optimal process conditions were as flows: preheating temperature $170{ }^{\circ} \mathrm{C}$, system pressure $70 \mathrm{~Pa}$, distillation temperature $200{ }^{\circ} \mathrm{C}$ and feeding rate $8 \mathrm{~kg} / \mathrm{h}$. under these conditions, the recovery of waste lubricating oil was more than $50 \%$. The regenerative oil compared with the waste lubricating oil, not only in appearance had obvious change, but also the contents of carbon residue, acid value declined substantially. The regeneration effect was remarkable, and the comprehensive utilization of resources was realized.

\section{Reference}

[1] C. B. Zhang, X. M. Zhang, X. B. Zhang, (2009), Application of inorganic membrane in the regeneration of waste lubricating oil, Journal of Chongqing Technology and Business University (Natural Science Edition), 4(26): 364-367. (In Chinese)

[2] V. Kanokkantapong, W. Kiatkittipong, B. Panyapinyopol, P. Wongsuchoto, P. Pavasant, (2009), Used lubricating oil management options based on life cycle thinking. Resources Conservation \& Recycling, 53(5), 294-299.

[3] Y. L. Hsu, C. C Liu, (2011), Evaluation and selection of regeneration of waste lubricating oil 
technology. Environmental Monitoring \& Assessment, 176(1-4), 197-212.

[4] K. J. Erdweg, (2005) Molecular and short- path distillation. Chemistry and Industry, 2(5):342345.

[5] L. P. Tovar, M. R. W. Maciel, G. M. F. Pinto, R. M. Filho, D. R. Gomes, (2010), Factorial design applied to concentrate bioactive component of cymbopogon citratus essential oil using short path distillation. Chemical Engineering Research \& Design Transactions of the Inst, 88(2), 239-244.

[6] P. Sbaite, C. B .Batistella, A. Winter, C. J. G. Vasconcelos, M. R. W. Maciel, R. M. Filho, et al. (2006), True boiling point extended curve of vacuum residue through molecular distillation. Petroleum Science \& Technology, volume 24(3), 265-274. 